\title{
Apresentação: Literatura infantil e ensino: polêmicas antigas e atuais
}

\author{
Elisa Maria Dalla-Bona* \\ Renata Junqueira de Souza**
}

No Brasil as publicações relativas às questões da relação entre literatura infantil e ensino foram raras antes dos anos de 1980. Merece destaque o pioneirismo de Cecília Meireles ao publicar, em 1951, Problemas da Literatura Infantil. Numa época de educação hegemonicamente tradicional na qual era marcante a ausência da literatura infantil na sala de aula ou quando estava presente era com o intuito da transmissão dos valores morais, a autora chama a atenção dos pais e professores dos pequenos leitores para a abundância de livros no mercado, mas muitos deles sem atributos literários.

Com um hiato de mais de uma década, Nelly Novaes Coelho publica, em 1966, a obra O Ensino da Literatura. O texto dialoga com os professores dos anos iniciais sobre novas alternativas metodológicas para o trabalho com a literatura infantil em sala de aula, ressalta sua importância na fase inicial da escolarização e alerta para a preocupação de um trabalho de valorização de histórias que visam a educar em detrimento do estímulo à fantasia e ao imaginário das crianças.

As preocupações das autoras se assemelham e perduram até nossos dias, principalmente aquelas relativas ao embate entre as finalidades atribuídas à literatura infantil que se dividem entre divertir, educar e instruir.

A escassa produção sobre literatura infantil e ensino pode ser reveladora do desinteresse dos pesquisadores, ou pior do desinteresse dos professores pelo tema. A literatura infantil raramente se fazia presente nas práticas escolares com as crianças, inclusive porque os acervos das instituições escolares eram pequenos ou, em alguns casos, inexistentes. E quando ela começa a fazer parte da escola "teve desviada sua função estética e passou a servir a propósitos educacionais restritos. E aqui se localiza o pecado original da literatura infantil: ter nascido

* Universidade Federal do Paraná. Setor de Educação. Programa de Pós-Graduação em Educação: Teoria e Prática de Ensino. Curitiba, Paraná, Brasil. E-mail: elisabona2@gmail.com. https://orcid.org/0000-0002-4320-1203

** Universidade Estadual Paulista “Júlio de Mesquita Filho". Programa de Pós-Graduação em Educação. Centro de Estudos em Leitura e Literatura Infantil e Juvenil. Presidente Prudente, São Paulo, Brasil. E-mail: recellij@gmail.com. https://orcid.org/0000-0003-2227-2544 
comprometida com a educação, em detrimento da arte." (AGUIAR, 1999, p. 243).

Seria, então, inconciliável a relação entre literatura infantil e ensino? Paiva $(1999$, p. 260) auxilia-nos a refletir sobre a questão. Ela afirma que se, por um lado, a "educação não deixa fluir a arte ou a escolariza, provocando pregnâncias pedagógicas inconciliáveis", de outro lado, é justamente este o desafio dos professores: "Ora, o nosso propósito então deve ser a tentativa de integrar estas duas instâncias [...] a fim de superarmos dicotomias." Este dossiê proposto para a Educar em Revista vai ao encontro dessa tentativa de conciliação e de contribuir para o crescimento de uma área carente de atenção. $O$ fato de uma revista como a Educar, em seus 40 anos de existência, ter publicado apenas dois artigos sobre a literatura infantil e ensino demonstra a sua pertinência.

Depois das discussões propostas por Cecília Meireles e Nelly Novaes Coelho, somente a partir dos anos de 1980 surgem algumas publicações dedicadas ao tema. Em relevo a importante contribuição da obra Leitura em crise na escola: as alternativas do professor (1982), organizada por Regina Zilberman. Conforme anuncia o título, debate-se a problemática relação entre leitura e escola, mas não se restringe às particularidades e especificidades da leitura literária, embora ela seja contemplada. Merece destaque um dos capítulos escrito por Marisa Lajolo, "O texto não é pretexto", em que a autora denuncia que a presença do texto literário no contexto escolar é artificial e, ao professor fazer do texto pretexto (aproveitamento para os exercícios de ortografia e gramática, aumento de vocabulário etc.), ele o descaracteriza e, como resultado, frequentemente verifica-se que o texto não apresenta significado nenhum para os alunos. A contribuição dessas reflexões de Lajolo encontra ecos até hoje, pois nas práticas escolares continua predominando o uso do texto como pretexto. Em Leitura em crise na escola: as alternativas do professor, os autores têm ainda a preocupação do fornecimento de sugestões práticas e alternativas de ação concreta para o professor superar o denunciado por Lajolo.

A editora Brasiliense criou a Coleção Primeiros Passos e, desde a década de 1970, publica títulos para abordar temas vigorosos e que atraem a atenção do público. Em 1986 lança $O$ que é literatura infantil, de Ligia Cademartori, um sinal de que o tema começava a despertar o interesse dos leitores. Nele a autora assevera que, pelo adjetivo "infantil", esta literatura era vista como algo inferior. Denuncia o fracasso escolar na formação de leitores e os interesses capitalistas do mercado editorial e, consequentemente, a banalização da literatura infantil e suas publicações conteudistas que distanciam as crianças da formação do senso crítico e do desenvolvimento cultural.

Maria Antonieta Antunes Cunha inaugura as publicações voltadas para as práticas em sala de aula. Por 20 anos a obra Literatura infantil: teoria e prática 
(1. a edição de 1983 e a 18. a de 2004) veio mostrando as dificuldades relativas à escassa bibliografia sobre a teoria da literatura infantil; o difícil acesso ao texto infantil; as poucas experiências de apoio para um trabalho prático e eficiente com a literatura para crianças e jovens.

Faz-se mister mencionar a contribuição crítica de Edmir Perrotti em uma de suas primeiras obras, O texto sedutor na literatura infantil (1986), porque analisa livros da literatura infantil e tece importantes reflexões sobre o trabalho do professor e a educação de crianças e jovens. Perrotti combate veementemente o crescente discurso utilitário que se sobrepõe ao discurso estético na literatura infantil. O "pedagogismo" pode ser resumido no tom professoral das histórias, sempre visando a ensinar algo para as crianças e apresentando o uso demagógico do final feliz. A presença desse discurso faz com que o discurso ficcional não se sustente até o final da obra, rompendo com importante condição da esteticidade.

Talvez pela abrangência do seu conteúdo e a linguagem acessível adotada no livro Literatura Infantil: gostosuras e bobices, Fanny Abramovich conseguiu a proeza de publicá-lo e republicá-lo por mais de uma década (1989 a 2001). Hoje se pode ler em sites de busca de livros na internet o apelo pelo livro que atualmente encontra-se esgotado. A obra ressalta a importância da literatura infantil e a necessidade de se disponibilizar livros para as crianças para que os manuseiem e se encantem com as ilustrações; valoriza a narração de histórias para as crianças se divertirem com os enredos de humor, sensibilizarem-se com as dificuldades enfrentadas por seus personagens e elaborarem seus sentimentos, além de aguçarem a sua capacidade crítica; e a autora salienta, ainda, a necessidade de encantar as crianças com a poesia. Essa obra enfatiza a função da literatura infantil como fruição, remando contra a corrente predominante do uso da literatura para os ensinamentos éticos, morais e, como anunciado por Marisa Lajolo em O texto não é pretexto, conteudistas.

O destaque no começo da década de 1990 fica com a obra Literatura. A formação do leitor: alternativas metodológicas (1993), de Maria da Glória Bordini e Vera Teixeira de Aguiar. Elas sugerem critérios para a seleção de textos literários, além de apresentarem cinco métodos de ensino de literatura, a partir de uma fundamentação teórica diferenciada, objetivos e parâmetros de avaliação específicos e etapas de sistematização das atividades em sala de aula. As alternativas metodológicas sugeridas são fundantes até os dias atuais para a formação dos professores e norteadoras das práticas de leitura literária diferenciadas em sala de aula.

Nessa época, Marly Amarilha publica o sucesso editorial Estão Mortas as Fadas? Literatura infantil e prática pedagógica. O livro foi editado pela primeira vez em 1997 e reeditado até 2012; ele aborda a problemática formação de leitores de literatura nas escolas e defende o fortalecimento da atuação do professor e a 
necessidade dele transformar a sala de aula em ambiente de leitura literária com vista à formação cognitiva, linguística, comunicativa e psicológica da criança.

As críticas à formação de leitores pela escola intensificaram-se com a divulgação dos resultados pífios do nível de leitura das crianças e jovens brasileiros, nas avaliações do Sistema de Avaliação da Educação Básica - Saeb - (desde 1990) e do Programa Internacional de Avaliação de Estudantes - Pisa - (desde 2000). Formou-se um consenso de que era preciso fazer alguma coisa para reverter a situação, e os professores passaram a ser pressionados pelos sistemas de ensino para que compreendessem que não bastava alfabetizar, era preciso formar leitores. A publicação, em 2006, do livro Letramento Literário. Teoria e prática, de Rildo Cosson, representou um alento para as discussões na área. As várias reimpressões da obra sinalizam o seu sucesso editorial. Com sua proposta de ensino de leitura literária na escola básica estruturada por meio de sequência didática básica e expandida, o autor aponta caminhos para o desenvolvimento do letramento literário na escola. Essas sequências têm servido como alternativa metodológica para os professores que, em eventos e dissertações, divulgam as suas iniciativas bem-sucedidas na construção de uma comunidade de leitores nas salas de aula brasileiras.

No início dos anos 2000 houve uma expansão das publicações relativas à literatura infantil e ensino que podem ter sido impulsionadas pelas significativas iniciativas governamentais que asseguraram a presença da literatura nas escolas. Sobressai-se o Programa Nacional Biblioteca da Escola (PNBE), uma importante ação do Ministério da Educação que, entre 1997 e 2014, promoveu o acesso à cultura e ao incentivo à leitura de alunos e professores por meio da distribuição de acervos de obras de literatura, de pesquisa e de referência. Não menos importante foi a divulgação, em 1997, dos Parâmetros Curriculares Nacionais (PCNs) e, em 2013, o Pacto Nacional pela Alfabetização na Idade Certa (Pnaic), porque preconizaram a necessidade e a relevância da leitura deleite. Pelo Pnaic as escolas também receberam um bom acervo de literatura infantil.

A coordenadora do PNBE, professora Aparecida Paiva, enfatiza nas suas diversas publicações (para citar apenas uma delas, Literatura Fora da Caixa. O PNBE na escola-Distribuição, circulação e leitura, 2012) que fazer os acervos de literatura chegarem às escolas era uma etapa fundamental para a formação de leitores, mas se ela não fosse acompanhada da formação de professores havia grande chance de os acervos não saírem das caixas. Nesse sentido, vale citar a criação dos mestrados profissionais em Educação que foram regulamentados a partir da Portaria número 80 de 1998 (Coordenação de Aperfeiçoamento de Pessoal de Nível Superior - Capes). O primeiro mestrado profissional em Educação foi criado em 2009 e hoje são 44 programas. Eles vêm provocando forte impacto para a formação na pós-graduação de professores da educação básica, 
como exemplo pode-se citar aquele da Universidade Federal do Paraná, com uma área de pesquisa em Letramento Literário e com vagas exclusivas a professores comprovadamente atuando no ensino fundamental. Na Universidade Federal de Minas Gerais (UFMG), além do mestrado profissional em Educação, existe um importante trabalho de formação de professores desenvolvido pelo Centro de Alfabetização, Leitura e Escrita (Ceale). A Universidade Estadual Paulista (Unesp - Presidente Prudente) () é uma instituição que vem se destacando nas iniciativas na área da literatura infantil e ensino, com inúmeras dissertações e teses defendidas sobre o tema e o Centro de Estudos em Leitura e Literatura Infantil e Juvenil "Maria Betty Coelho Silva" (Cellij), que, desde 1995, desenvolve ações com o objetivo principal de formar leitores a partir do texto literário.

Crescem também os eventos na área da literatura infantil e com eles a possibilidade de aproximação dos interessados no tema e divulgação de trabalhos produzidos no Brasil e no exterior. Para citar apenas os dois maiores e que em suas últimas edições reuniram em torno de mil participantes: o Congresso Internacional de Literatura Infantil e Juvenil promovido pelo Cellij, coordenado pela professora Renata Junqueira de Souza, da Unesp de Presidente Prudente/ São Paulo. O primeiro congresso foi em 1999 e ocorre ininterruptamente a cada dois anos, promovendo a discussão sobre o ensino da leitura, a qualidade da produção dos livros infantis e juvenis e a importância da literatura infantil e juvenil como material de leitura; e o Seminário de Literatura Infantil e Juvenil (Slij), coordenado pela professora Eliane Debus, da Universidade Federal de Santa Catarina/Florianópolis. O 1. ${ }^{\circ}$ Slij ocorreu em 2001 e bienalmente vem reunindo interessados no estudo da leitura, das práticas educativas construídas em diálogo com a literatura infantil e juvenil e formação do leitor de literatura infantil e juvenil.

Embora, como vimos, tenha ocorrido a intensificação das publicações sobre a relação da literatura infantil com o ensino, ainda estamos longe de ter uma farta produção na área. Ao contrário, os estudos de literatura infantil ainda são marginalizados pelos teóricos, temos uma carência de pesquisas e publicações sobre o tema e premência por preencher as lacunas teóricas e práticas na formação dos professores que trabalham com as crianças em fase inicial de escolarização.

Loyola (2013, p. 113) afirma que a relação entre literatura e ensino é paradoxal e esbarra em polêmicas antigas e profundas, "apesar da convivência secular, possuem dinâmicas próprias e, na maioria das vezes, divergentes". Magda Soares, em 1999, já havia publicado um capítulo intitulado "A escolarização da literatura infantil e juvenil" para alertar sobre essas divergências, afirmando que a literatura é essencialmente questionadora e libertadora e, por outro lado, a escola é autoritária e reacionária. 
Soares (1999) cita Nelly Novaes Coelho, uma das pioneiras desta discussão, para esclarecer este papel libertador da literatura: "a partir de meados dos anos 70, o livro infantil se tornou "uma leitura que, mais do que simples divertimento, é um fecundo instrumento de formação humana, ética, estética, política, etc.", e a literatura infantil "oferece matéria extremamente fecunda para formar ou transformar as mentes." (SOARES, 1999, p. 19). E, para definir a tendência da escola ao autoritarismo e reacionarismo, a autora trata da imprópria escolarização da literatura, "que se traduz em sua deturpação, falsificação, distorção, como resultado de uma pedagogização ou uma didatização mal compreendidas que, ao transformar o literário em escolar, desfigura-o, desvirtua-o, falseia-o." (SOARES, 1999, p. 22).

Apesar dessa relação “conflituosa”, é inegável, como afirma Loyola (2013, p. 113), que "a escola tornou-se a responsável pela habilitação do leitor e pela sua iniciação na educação literária", não obstante os problemas daí decorrentes, sendo o mais contundente deles, "a vinculação das atividades de leitura a conteúdos morais ou a conceitos de natureza não artística.” (p. 114). Esses empasses podem ser enfrentados com investimentos na formação dos professores que atuam com as crianças pequenas na educação infantil e nos anos iniciais do ensino fundamental, pois eles são os "responsáveis por introduzir a criança no universo da leitura literária, tão decisiva para a formação humana, na sua dimensão mais ampla, profunda e bela." (LOYOLA, 2013, p. 122). Reunir num dossiê temático, numa revista com a credibilidade e capilaridade da Educar, artigos sobre a relação entre a literatura infantil e o ensino deve se constituir num material auxiliar para essa formação.

A retrospectiva histórica apresentada até aqui teve o intuito de sintetizar os assuntos afetos às questões da literatura infantil e o ensino e salientar que eles continuam atuais, como veremos nos artigos do dossiê.

Literatura, literatura infantil e valores: da inculcação à interrogação, de Max Butlen, afirma que a literatura infantil há muito tem sido classificada como um gênero menor e sujeita a julgamentos desfavoráveis que a desqualificaram como objeto de ensino literário respeitável. Assim, admitir aos círculos acadêmicos e às instituições escolares francesas que a literatura infantil pode ser valiosa foi e continua sendo uma luta travada por bibliotecários, profissionais do livro e da leitura, professores, associações de ativistas culturais, de movimentos pedagógicos e de educação popular que identificaram o problema social e cultural da insuficiência, qualitativa e quantitativa, da oferta de leitura oferecida aos jovens. Dessa luta resultou o fortalecimento da literatura infantil, que passou a fazer parte dos textos oficiais da educação nacional francesa no final do século XX. O desejo de conquistar e reter o público leitor jovem vem sendo acompanhado por um distanciamento crescente da ideia de que a literatura infantil deveria ter uma 
função edificante, resultando na repetida inculcação de valores. A postura ética muda de natureza se torna menos restritiva e muito mais tolerante para abordar tópicos mais divisivos como a exploração do homem pelo homem, o prazer, os diferentes aspectos da sexualidade, a doença, a morte, a violência social. A leitura ética ou moral da literatura e a criação e transmissão de valores por meio dela têm sido repensadas em novas bases, trata-se de passar de uma postura de inculcação de valores para sua interrogação. Agora é necessário revalorizar o que está no cerne da prática cultural da leitura, a saber, sua relação com a vida, os homens, os comportamentos humanos, sua capacidade de produzir emoções, sua função de questionar a identidade e os valores de cada leitor. $\mathrm{O}$ artigo apresenta os estudos na área da didática da leitura literária que valorizam o leitor, também considera uma turma de alunos como uma comunidade de leitores com potencial para o debate em sala de aula, para a expressão de opiniões, de diferentes reações e reflexões diante de um mesmo texto e valorizam a capacidade do professor de provocar a participação dos alunos. Neste ambiente os alunos podem, por exemplo, durante um debate, reconsiderar seus juízos éticos e estéticos, os do autor, os dos outros leitores, apreciando os efeitos programados pelo texto para mover, convencer ou provocar uma interrogação de valores.

Análise de obras da literatura infantil como estratégia de formação do pedagogo/professor: saber ler, saber escolher, de Elisa Maria Dalla-Bona e Jair Tadeu da Fonseca, apresenta um estudo de caso na disciplina "Metodologia do ensino da literatura infantil", no curso de Pedagogia da Universidade Federal do Paraná (Brasil). Constata que predomina entre os estudantes a ideia utilitarista do trabalho escolar com a literatura infantil e seu uso como pretexto para ensinar os conteúdos escolares. Nas aulas, a partir de alguns princípios oriundos da teoria da estética da recepção e seus impactos para o ambiente escolar, são confrontadas obras consideradas de boa e de má qualidade. $\mathrm{O}$ artigo analisa cinco delas (Luanda enroladinha, Obax, Pra saber voar, O monstro monstruoso da caverna cavernosa, $O$ Grúfalo) e ressalta a efetividade deste estudo comparativo para desestabilizar os estudantes e os auxiliar a pensar sobre o papel da literatura infantil no ensino e na formação do jovem leitor.

O pato, a morte e a tulipa - Leitura e discussão de um livro ilustrado desafiador com alunos dos anos iniciais, de Edgar Roberto Kirchof e Rosa Maria Hessel Silveira, aborda o tema morte ao relatar experiências de leitura literária desenvolvidas com duas turmas de $4 .^{\circ}$ ano de ensino fundamental em escolas públicas de Porto Alegre (RS). Assevera que a temática da morte sempre esteve presente nos livros produzidos para crianças, mas, desde o século XIX, com o fortalecimento da visão burguesa que considera a infância como uma fase frágil, nos livros infantis a morte passou a ser representada de forma mais amena e, em muitos casos, transformou-se em um tabu para o público infantil, 
por se tratar de um tema supostamente difícil, com o qual se acreditava que as crianças não estariam preparadas para lidar. Por outro lado, nos últimos anos, ao menos no mercado editorial, tal concepção vem se modificando radicalmente, pois a morte parece ter se transformado em um tema não apenas aceitável, mas inclusive recomendável para ser abordado em livros infantis. Analisa a recepção e a discussão do livro ilustrado $O$ pato, a morte e a tulipa, de Wolf Erlbruch, e conclui que esse livro pode ser considerado um contraponto em relação às representações estereotipadas da morte que são colocadas para circular em meios de comunicação de massa endereçados a crianças, proporcionando a possibilidade de desconstruir clichês e estereótipos construídos visualmente para fazer circular a ideia da morte como algo macabro e aterrador; e um contraponto na medida em que não fornece consolos confortantes e tampouco explicações religiosas, instigando o leitor a refletir e a chegar às suas próprias conclusões. As crianças participantes da pesquisa foram capazes de desconstruir vários elementos que compõem as representações da morte, principalmente a associação entre a morte e o medo.

Em busca da relação (im)possível: entre a educação literária e a educação artística, de Mafalda Franco e Ângela Balça, relata uma investigação-ação desenvolvida com crianças que frequentavam o $2 .^{\circ}$ ano do ensino básico em Portugal, com o objetivo de promover não só uma educação literária, mas também uma educação artística. Constata que a educação artística é relegada na educação escolar e que um trabalho adequado com a literatura infantil pode integrar a educação literária e a artística. Denuncia que, na escola, a literatura não é encarada como uma arte, e que a literatura infantil, em particular, serve para múltiplos propósitos e a maioria das vezes não promovem a educação literária. Descreve algumas intervenções realizadas com as crianças usando duas obras da literatura infantil portuguesa: Quando eu nasci, de Isabel Minhós Martins e Madalena Matoso, e Os animais fantásticos, de José Jorge Letria e André Letria. Esses livros foram escolhidos porque favoreceram aliar o texto plástico ao texto verbal. As intervenções permitiram o desenvolvimento nas crianças da sua educação artística (manifestaram-se a partir da expressão plástica e da expressão dramática) aliada à sua educação literária (leram, participaram ativamente no debate, mobilizaram conhecimentos prévios, partilharam informações, expressaram sentimentos e ideias, compararam inferências de leitura). Mostra a possibilidade de articulação entre duas áreas curriculares consideradas distintas, mas afinal muito próximas, estimulando a ligação entre a obra literária e as expressões artísticas.

Os professores anseiam por teorias que lhes deem suporte para as suas ações pedagógicas com a formação de leitores em sala de aula. $\mathrm{O}$ artigo $O$ Cantinho da Leitura como prática de letramento literário, de Renata Junqueira de 
Souza e Rildo Cosson, denuncia a frágil formação universitária dos professores que não contempla o conhecimento específico da metodologia do ensino da literatura; o percurso formativo, pouco afeito à presença da literatura, decorre que os professores terminam por não se constituírem como leitores literários e têm muita dificuldade de trabalhar com literatura com seus alunos; o uso do livro didático enquanto instrumento de ensino da leitura literária; a ausência nas orientações curriculares oficiais da especificidade do ensino de literatura nos anos iniciais do ensino fundamental, e a literatura como mera coadjuvante no ensino de língua. Por essas razões o ensino da literatura nos anos iniciais do ensino fundamental permanece preso a duas perspectivas, ambas alvo de críticas: a utilitária, do ensinar alguma coisa por meio do texto literário; e a idealista, que seria a melhor maneira de inserir a literatura na escola evitando os riscos da pedagogização e abster-se de qualquer propósito formativo, ou seja, apenas dando acesso às obras para que os alunos se "deleitem" com elas. Diante desse quadro tão pouco favorável ao ensino da literatura nos anos iniciais do ensino fundamental, os autores apontam como alternativa o letramento literário. Apresentam uma prática específica de cantinho da leitura, que criou as condições para que uma escola se transformasse num espaço privilegiado de formação de leitores literários e os alunos em autênticos leitores autônomos.

O tema "estratégia de leitura" vem despontando no foco de interesse de profissionais da Educação e demais pesquisadores com vistas à formação de leitores proficientes e autônomos e, nessa direção, muitos estudos, principalmente sob a influência de autores como Solé, Kato, Kleiman, Koch e Elias, Girotto e Souza, têm sido realizados no Brasil; essa afirmação está no artigo "Estratégias de leitura - estado da arte", de Sílvia de Fátima Pilegi Rodrigues, que apresenta um balanço de uma pesquisa do tipo estado da arte sobre "estratégias de leitura", tomando como referência publicações constantes em três bases: teses e dissertações publicadas na BDTD, anais de dois eventos nacionais (Anped e Cole) e artigos de periódicos que constassem na Scielo, com a demarcação temporal de 2000 a 2017.

A formação de professores é abordada em dois artigos. La formación básica de docentes de educación infantil en lengua escrita y literatura. El caso de la $U A B$, de Neus Real e Maria Rosa Gil, apresenta um estudo de caso desenvolvido com os estudantes da Faculdade de Ciências da Educação da Universidade Autônoma de Barcelona, matriculados nos anos de 2017 e 2018 na disciplina "Didática da língua escrita e a literatura na educação infantill, que havia sido reformulada para atender às demandas da formação docente. Os instrumentos de investigação aplicados aos participantes antes da realização da disciplina constataram as suas limitações para o ensino da língua escrita e da literatura na educação infantil. Ao término da disciplina, as suas respostas 
ao instrumento de pesquisa comprovaram a sua evolução, embora ainda sejam necessárias adequações na disciplina para aperfeiçoar aspectos da formação dos professores. Nas aulas, os estudantes aprenderam os conhecimentos essenciais sobre como as crianças se apropriam do código escrito, como promover o protagonismo infantil, analisaram livros de literatura infantil, e também a maneira de mobilizar as crianças em sala de aula para progredirem como leitores. Após cursar a disciplina, eles demonstraram estarem melhor preparados para trabalhar adequadamente com a primeira aprendizagem da língua escrita e os fundamentos iniciais da educação literária.

O ensino de literatura no curso de Pedagogia: uma presença necessária, de Diana Maria Leite Lopes Saldanha e Marly Amarilha, examina a evolução na qualidade da produção literária para crianças e jovens de autores brasileiros, mas essa produção carece de leitores. As escolas não têm sido capazes de formá-los, fato comprovado pelo desempenho insatisfatório em leitura dos estudantes brasileiros no Programa Internacional de Avaliação de Estudantes (Pisa) e no Índice de Desenvolvimento da Educação Básica (Ideb). O mapeamento do ensino de literatura feito pelas autoras nos cursos de Pedagogia de 27 universidades federais brasileiras constata a fragilidade teórica e prática na formação dos pedagogos para o trabalho com a literatura infantil, fato determinante para a precária formação escolar de leitores de literatura.

Esses artigos contemplam reflexões sobre temas muito caros para aqueles que se preocupam com a formação de leitores nas escolas e principalmente discutem problemas que há muito tempo insistem em permanecer nas salas de aula (o uso do texto como pretexto, a falta de professores leitores, atividades de leitura utilitárias), mas apontam soluções viáveis para o ensino da literatura e para a constituição de leitores literários.

\section{REFERÊNCIAS}

ABRAMOVICH, Fanny. Literatura Infantil: gostosuras e bobices. São Paulo: Scipione, 1989.

AGUIAR, Vera Teixeira de. Leitura literária e escola. In: EVANGELISTA, Aracy et al. A escolarização da leitura literária: o jogo do livro infantil e juvenil. Belo Horizonte: Autêntica, 1999. p. 235-255.

AGUIAR, Vera Teixeira de; BORDINI, Maria da Glória. Literatura. A formação do leitor: alternativas metodológicas. 2. ed. Porto Alegre: Mercado Aberto, 1993. 
AMARILHA, Marly. Estão Mortas as Fadas? Literatura infantil e prática pedagógica. Petrópolis: Vozes; Natal: EDUFRN/Cooperativa Cultural, 1997.

LOYOLA, Juliana Silva. Literatura na formação do leitor: perspectivas para a educação básica. In: BARBOSA, Juliana Bertucci; BARBOSA, Marinalva Vieira (Orgs.). Leitura e mediação. Reflexões sobre a formação do professor. Campinas, São Paulo: Mercado de Letras, 2013. p. 113-124.

CADEMARTORI, Ligia. O que é literatura infantil. São Paulo: Brasiliense, 1986.

COELHO, Nelly Novaes. O Ensino da Literatura. São Paulo: FTD, 1966.

COSSON, Rildo. Letramento Literário. Teoria e prática. São Paulo: Contexto, 2006.

CUNHA, Maria Antonieta Antunes. Literatura infantil: teoria e prática. São Paulo: Ática, 1983.

LAJOLO, Marisa. O texto não é pretexto. In: ZILBERMAN, Regina (Org.). A leitura em crise na escola: as alternativas do professor. Porto Alegre: Mercado Aberto, 1982. p. 51-62.

MEIRELES, Cecília. Problemas da Literatura Infantil. Belo Horizonte: Imprensa Oficial, 1951.

PAIVA, Aparecida (Org.). Literatura fora da caixa. O PNBE na escola - distribuição, circulação e leitura. São Paulo: Editora UNESP, 2012.

PAIVA, Aparecida. Estatuto literário e escola. In: EVANGELISTA, Aracy et al. $A$ escolarização da leitura literária: o jogo do livro infantil e juvenil. Belo Horizonte: Autêntica, 1999. p. 257-261.

PERROTTI, Edmir. O texto sedutor na literatura infantil. São Paulo: Ícone, 1986.

SOARES, Magda. A escolarização da literatura infantil e juvenil. EVANGELISTA, Aracy et al. A escolarização da leitura literária: o jogo do livro infantil e juvenil. Belo Horizonte: Autêntica, 1999. p. 17-48.

ZILBERMAN, Regina (Org.). A leitura em crise na escola: as alternativas do professor. Porto Alegre: Mercado Aberto, 1982. 